УДК 378.147+372.87+004

\title{
ДИСТАНЦИОННЫЕ ОБРАЗОВАТЕЛЬНЫЕ ТЕХНОЛОГИИ В ХОРЕОГРАФИЧЕСКОМ ОБРАЗОВАНИИ: ПРОБЛЕМЫ И ВОЗМОЖНОСТИ
}

\begin{abstract}
Алферов Андрей Александрович
к.п.н., доцент, заслуженный артист Российской Федерации, декан исполнительского факультета, профессор кафедры классического и дуэтного танца ФГБОУ ВО «Московская государственная академия хореографии»
\end{abstract}

Аннотация: В статье рассматриваются проблемы и возможности применения дистанционных образовательных технологий в процессе обучения классическому танцу, а также при отборе лиц, поступающих на обучение в образовательные организации, реализующие образовательные программы среднего профессионального образования и дополнительного образования в области хореографического искусства.

Ключевые слова: дистанционные образовательные технологии, хореографическое искусство, хореографическое образование, классический танец, Московская государственная академия хореографии.

\section{DISTANCE LEARNING TECHNOLOGIES IN CHOREOGRAPHIC EDUCATION: PROBLEMS AND OPPORTUNITIES}

\section{Alferov Andrey Aleksadrovich}

\begin{abstract}
The article deals with the problems and possibilities of using distance learning technologies in the process of teaching classical dance, as well as the selection of individuals who are enrolled in educational organizations that implement educational programs of secondary professional education and additional education in the field of choreographic art.
\end{abstract}

Key words: distance learning technologies, choreographic art, choreographic education, classical dance, Moscow State Academy of Choreography. 
В условиях борьбы с коронавирусом постоянно ведутся дискуссии о возможности/невозможности образования в дистанционном формате особенно в области хореографического искусства. Однако существует целый ряд объективных требований, которые образовательные организации должны выполнять, например: срок реализации образовательной программы, план приема на обучение, договорные обязательства субъектов образовательного процесса. В связи с этим необходим поиск и апробирование методов и способов реализации образовательных программ в дистанционном формате, а также дистанционного отбора лиц, поступающих на обучение.

Как показывает опыт Московской государственной академии хореографии (далее также - МГАХ), при решении задач, связанных с дистанционным образованием, следует, прежде всего, определить очередность и важность того или иного аспекта образовательного процесса. Например: спецификой хореографического образования является необходимость соответствующей материально-технической базы: балетный (танцевальный) зал, по площади соответствующий нормативам и количеству обучающихся в группе, наличие хореографических (балетных) станков, зеркал для самоконтроля исполнения движений, музыкального инструмента (рояль) или звуковоспроизводящей техники для обеспечения музыкального сопровождения учебных занятий. В связи с этим для организации учебных занятий по классическому танцу с применением дистанционных образовательных технологий преподавателю сначала необходимо пересмотреть календарно-тематический план дисциплины с учетом таких новых условий, как: ограниченность пространства (обучающийся находится не в балетном зале, а дома); обеспечение аппаратно-программными средствами (компьютер, программное обеспечение видео-конференцсвязи); обеспеченность субъектов образовательного процесса техническими средствами (балетный станок, зеркало) и др. Разработка календарнотематического плана на этапе реализации программы с применением дистанционных образовательных технологий по учебной дисциплине «Классический танец» может ограничиваться изучением движений, исполняемых на месте, или с минимальным продвижением, комбинированием учебного материала с учетом ограниченности пространства.

Одной из выявленных проблем реализации программы по классическому танцу в дистанционном формате также можно отметить запаздывание звука музыкального сопровождения урока. Проблему можно 
разделить на две части: 1) педагог слышит звук, который опаздывает или приходит раньше, чем обучающийся исполнил движение; 2) учащийся слышит звук, который приходит раньше или позже, чем преподаватель считает вслух. Для решения проблемы рекомендуем учесть, что все учащиеся и студенты уже имеют опыт обучения в очном формате в балетном зале. Следовательно, у них уже должны быть сформированы определенные умения и навыки исполнения движений с музыкальным сопровождением, поэтому нет необходимости считать вслух при проведении дистанционных занятий, так как прогнозировать своевременность и одновременность счета преподавателя и сопровождения концертмейстера в условиях их нахождении в разных помещениях мы не сможем. Обучающийся слышит музыку и исполняет движение в соответствии с ранее сформированным навыком. Учитывая это, учебное время необходимо распределить на формирование других умений и навыков (например, таких, как: выворотность позиций ног, правильность положений и переводов рук из одной позиции в другую, разучивание различных движений, связанных с усложнением координирования ранее изученных элементов и пр.).

Исходя из практики применения технологий дистанционного образования в Московской государственной академии хореографии в период приемной кампании, можем также выделить несколько аспектов, на которые необходимо обратить внимание:

1. Процесс организации приемной кампании в дистанционном формате требует своевременной обработки большого массива данных, что необходимо предусмотреть в объеме работы приемной комиссии.

2. Процедура отбора предполагает наличие у преподавателей (членов комиссии по отбору лиц, поступающих на обучение) умений и навыков владения программно-аппаратными средствами, необходимыми для реализации дистанционных образовательных технологий.

3. Процедура проведения отбора в дистанционном формате не должна противоречить действующим нормативным документам.

4. Применение дистанционных образовательных технологий должно быть возможно как для обеспечения просмотра поступающих, так и для проведения заседаний комиссии по отбору лиц.

5. С учетом различных возможностей лиц, поступающих на обучение, в части материально-технического обеспечения, возможно представление материалов в формате видеопрезентаций (видеопортфолио). С целью 
обеспечения выполнения одинаковых условий отбора, образовательной организации необходимо разработать регламент для представляемых видеопрезентаций как в части времени, так и в части их содержания. При разработке регламента следует определить ракурсы и положения поступающего, точки и ракурсы съемки, содержание фона, присутствие в помещении посторонних лиц, иные существенные условия. Содержание видеопрезентации должно позволить комиссии произвести объективную оценку профессионально значимых качеств по установленным образовательной организацией параметрам, которые, в свою очередь, должны обеспечить выполнение государственных требований [1].

При проведении отбора лиц для обучения по программам в области хореографического искусства члены комиссии ежегодно сталкиваются с проблемой большого количества поступающих и ограниченного времени для выставления оценки. Из практики же проведения отбора на обучение в МГАХ в 2020 году следует отметить положительную сторону применения дистанционных образовательных технологий: каждый член комиссии имеет доступ к любой видеопрезентации и может анализировать данные каждого поступающего, просматривая запись несколько раз и сравнивая профессионально значимые качества поступающих, чтобы обеспечить «зачисление в образовательную организацию лиц, обладающих выдающимися способностями в области искусств и физическими качествами, необходимыми для освоения соответствующих интегрированных образовательных программ в области искусств», что, в частности, предусмотрено пунктом 11 «Порядка отбора лиц для приема на обучение по образовательным программам среднего профессионального образования, интегрированным с образовательными программами основного общего и среднего общего образования» [1, c. 2].

Следует отметить, что ответственность в части подготовки видеозаписи (видеопрезентации к дистанционному отбору) ложится на родителей, обеспечивающих видеосъемку, ассистирование при показе и подготовку видеопрезентации. Образовательная организация вправе создавать соответствующие рекомендации для родителей, разъясняющие цели и задачи тех или иных положений, правильность их исполнения и параметры, оцениваемые комиссией по отбору. При создании видеопрезентации (видеопортфолио) лица, поступающие на обучение, имеют возможность провести съемку неоднократно, выбирая на свое усмотрение лучшую. При очном же проведении отбора комиссия осуществляет просмотр абитуриента 
один раз, выставляя оценку в протокол, и далее ориентируется только на параметры и оценку, указанные в протоколе.

Также в дистанционном формате в 2020 году в МГАХ осуществлялась работа медицинской комиссии, обеспечивающей организацию отбора лиц, поступающих на обучение, с учетом состояния их здоровья. На основании «Перечня заболеваний, патологических состояний, функциональных расстройств, особенностей физического развития, препятствующих поступлению на обучение и обучению по дополнительным общеобразовательным и основным профессиональным образовательным программам в области хореографического искусства» [2] специалистами МГАХ был скорректирован традиционный («очный») регламент отбора, и медицинская комиссия работала с применением дистанционных технологий.

Подводя итоги вышеизложенному, можно отметить, что положительные аспекты проведения отбора лиц, поступающих на обучение, с использованием дистанционных образовательных технологий в сочетании с традиционным отбором позволяет расширить круг решаемых задач, в том числе и в условиях борьбы с коронавирусом, обеспечить возможность дополнительного контроля оформления необходимой документации членами комиссий, оптимизировать занятость профессорско-преподавательского состава в период проведения отбора, использовать сравнительные показатели по различным параметрам отбора на этапе подведения итогов с использованием видеопрезентаций, представленных лицами, поступающими на обучение.

\section{Список литературы}

1. Порядок отбора лиц для приема на обучение по образовательным программам среднего профессионального образования, интегрированным с образовательными программами основного общего и среднего общего образования [Электронный ресурс] : Приложение к Приказу Министерства культуры Российской Федерации от 25.11.2013 г. № 1950 // Министерство культуры Российской Федерации [Сайт]. - URL: https:/culture.gov.ru /documents/ob_utverzhdenii_poryadka_otbora_352808/ (дата обращения: 03.10.2020).

2. Перечень заболеваний, патологических состояний, функциональных расстройств, особенностей физического развития, препятствующих поступлению на обучение и обучению по дополнительным общеобразовательным и основным профессиональным образовательным программам в области хореографического искусства [Электронный ресурс] / 
ФГАУ «НМИЦ здоровья детей» Минздрава России; ФГБОУ ВО «Московская государственная академия хореографии». - М., 2019. - 21 с. // Московская государственная академия хореографии [Сайт]. - URL: http://balletacademy. ru/obrazovanie/srednee-professionalnoe-obrazovanie/perechen-zabolevanijprepyatstvuyushhih-postupleniyu-v-horeograficheskoe-uchilishhe (дата обращения: 03.10.2020).

(C) А.А. Алферов, 2020 